\title{
Microbial Water Relations. Effects of Solute Concentration on the Respiratory Activity of Sugar-tolerant and Non-tolerant Yeasts
}

\author{
By A. D. BROWN* \\ School of Microbiology, University of New South Wales, \\ Kensington, N.S.W. 2033, Australia
}

(Received 25 June 1974)

SUMMARY

The respiratory activity of the sugar-tolerant (osmophilic) yeast, Saccharomyces rouxii, and the non-tolerant species, Sacchromyces cerevisiae, were compared after growth in a complex basal medium, the medium supplemented with polyethylene glycol (mol. wt 200) to give a water activity of 0.95 , and the medium supplemented with glucose $(24$ and $36 \%, \mathrm{w} / \mathrm{v})$. The properties compared were $Q_{\mathrm{o}_{2}}$ (glucose), NADH oxidase activity of isolated mitochondrial fractions, and cytochrome content. When grown in the basal medium $S$. cerevisiae was somewhat more active than $S$. rouxii by all criteria. Growth in the media supplemented were high glucose concentrations produced catabolite repression of respiration in $S$. cerevisiae but not in $S$. rouxii. The implications of this difference for polyol biosynthesis and the water relations of the sugar-tolerant species are discussed.

\section{INTRODUCTION}

Apart from their water relations, the sugar-tolerant ('osmophilic') yeasts differ from related non-tolerant species in several ways. Their growth rates under optimal conditions are substantially less than the corresponding growth rates of non-tolerant species (Anand \& Brown, I968). Further, the tolerant yeasts produce polyhydric alcohols, sometimes in high yields (Onishi, I963; Spencer, 1968). The polyols are substantially retained by the yeasts and can reach a high intracellular concentration. In their role as compatible solutes, they are a major determinant of the water relations of the tolerant species (Brown \& Simpson, I972; Brown, 1974). There is, however, an apparent biochemical anomaly in polyol production by these organisms. In spite of the fact that the polyhydric alcohols are essentially fermentation end-products, their synthesis requires an adequate supply of oxygen; at low oxygen tension and sugar-tolerant yeasts revert to a normal ethanolic fermentation (Onishi, I963; Spencer, I968).

These observations, together with the conspicuous ability to grow well in high concentrations of many types of sugar, including glucose, where catabolite repression might be expected, suggested that the composition and/or biosynthesis of the respiratory apparatus of the tolerant yeasts might differ from that of their non-tolerant counterparts.

This paper compares the formation and function of the respiratory apparatus of the sugartolerant yeast, Saccharomyces rouxii, with that of the closely similar non-tolerant $S$. cerevisiae.

* Present address: Department of Biology, University of Wollongong, Wollongong, New South Wales, 2500, Australia. 


\section{METHODS}

Organisms. Saccharomyces rouxii (strain YA: Anand \& Brown, I968) and S. cerevisiae (strain Y4I ; Anand \& Brown, I968) were used throughout. Stock cultures were maintained at 2 to $4{ }^{\circ} \mathrm{C}$ on 'synthetic honey agar' and malt agar respectively (Anand \& Brown, 1968). The yeasts were cultured on a rotary shaker $(200 \mathrm{rev} . / \mathrm{min})$ at $30^{\circ} \mathrm{C}$ to mid-exponential phase in basal medium (Anand \& Brown, 1968) and in the same medium supplemented with glucose as indicated or with polyethylene glycol [mol. wt $200,33.5 \%(\mathrm{w} / \mathrm{w})$, water activity $\left(a_{\mathrm{w}}\right)$ 0.95]. Polyethylene glycol was deionized (Anand \& Brown, 1968) before use. Conical flasks ( 21 nominal capacity) were used throughout and contained I 1 growth medium. Before harvesting, cultures were cooled in ice and then centrifuged briefly at $13200 \mathrm{~g}$ and $\circ{ }^{\circ} \mathrm{C}$. Harvested pellets were washed for specific purposes as described below.

Whole yeast respiration. Each culture was halved. After growth in basal medium one half was washed three times at $0^{\circ} \mathrm{C}$ in phosphate buffer $\left(\mathrm{Na}^{+}+\mathrm{K}^{+}, 0.067 \mathrm{M}, \mathrm{pH} 5.9, a_{\mathrm{w}} 0.997\right)$ and resuspended in the buffer at $0{ }^{\circ} \mathrm{C}$ (suspension A). The other half was washed in phosphate buffer, in buffer containing $\mathrm{I} 6.8 \%(\mathrm{w} / \mathrm{w})$ polyethylene glycol (PEG, mol. wt 200) and in buffer plus $33.5 \%(\mathrm{w} / \mathrm{w})$ PEG $\left(a_{\mathrm{w}}\right.$ approximately 0.95$)$; it was finally suspended in buffer plus $33.5 \%$ PEG (suspension B). After growth in media containing glucose $(36$ or $48 \%$, w/v) or PEG, suspension A was prepared by washing once in buffer plus $33.5 \%$ (w/w) PEG, once in buffer plus $16.8 \%$ PEG, and once in buffer; it was finally resuspended in buffer. Suspension B was prepared by washing three times, as after growth in basal medium, and suspending in buffer plus $33.5 \%$ PEG. After growth in $24 \%(\mathrm{w} / \mathrm{v})$ glucose, suspension A was washed once in buffer plus $16.8 \%$ PEG, once in buffer plus $8.4 \%$ PEG and once in buffer, and finally resuspended in buffer. The other half was washed three times, as for suspension $B$ after growth in basal medium, and resuspended in buffer plus $16.8 \%$ PEG (suspension $\mathrm{C}$ ).

For each wash the suspension was centrifuged briefly at $\mathrm{I} 2000 \mathrm{~g}$. The yeast concentration in the final suspension was usually within the range 6 to $\mathrm{I} 8 \mathrm{mg}$ dry wt/ml. The respiration rate $\left(Q_{\mathrm{o}_{2}}\right)$ was determined at $30^{\circ} \mathrm{C}$ in the presence of glucose by conventional manometric techniques. The suspending buffer was always the same as that used for the final suspension of the yeast (suspension A, buffer; suspension B, buffer plus $33.5 \%$, w/w, PEG; suspension $\mathrm{C}$, buffer plus $\mathrm{I} 6.8 \%$, w/w, PEG).

NADH oxidase assay. NADH oxidase was assayed in mitochondrial fractions prepared as follows. Yeast grown in basal medium was harvested, washed once in phosphate buffer $\left(\mathrm{Na}^{+}+\mathrm{K}^{+}, 0.0 \mathrm{I} 5 \mathrm{M}, \mathrm{pH} 7.4\right)$ and once in tris- $\mathrm{HCl}(0.02 \mathrm{M}, \mathrm{pH} 7.2)$ containing the following substances added to the buffer in the order stated: sucrose $(0.5 \mathrm{M})$, EDTA (sodium salt, $0.002 \mathrm{M})$ and magnesium chloride $(0.002 \mathrm{M})$. Yeast grown in media containing polyethylene glycol or glucose at a high concentration was washed in graded solutions of buffered polyethylene glycol, as for the respiration experiments, once in phosphate buffer alone, and finally in the tris- $\mathrm{HCl}+$ sucrose buffer as above. The yeast pellet was transferred to a press (see Anand, 1969) at the temperature of solid $\mathrm{CO}_{2}$ and disrupted. The ruptured yeast was thawed by resuspending in a minimal volume of the tris + sucrose buffer at $0^{\circ} \mathrm{C}$ and thoroughly dispersed with a glass-Teflon homogenizer. The suspension was centrifuged at $0{ }^{\circ} \mathrm{C}$ briefly at $7700 \mathrm{~g}$ and the supernatant retained. The pellet was resuspended and washed once more in the centrifuge under the same conditions. The two supernatant fractions were combined and centrifuged for $15 \mathrm{~min}$ at 70000 to $80000 \mathrm{~g}$. The pellet was resuspended with a glass-Teflon homogenizer to a protein concentration of 7 to II $\mathrm{mg} / \mathrm{ml}$ in tris + sucrose buffer. This suspension was the mitochondrial fraction used for the assay of NADH oxidase. 
It was stored frozen if necessary; there was no loss of activity in the frozen state for at least two weeks.

NADH oxidase was assayed conventionally at $30{ }^{\circ} \mathrm{C}$ by measuring the rate of diminution of extinction at $340 \mathrm{~nm}$. The assay mixture contained $(\mathrm{ml})$ : tris- $\mathrm{HCl}$ buffer $(\mathrm{O} \cdot \mathrm{I} \mathrm{M}, \mathrm{pH} 7 \cdot 70)$, 0.50 ; EDTA (sodium salt, $2.0 \mathrm{mM}$ ), $0.20 ; \mathrm{MgCl}_{2}$ (0.0I M), 0.05; water, 0.20; enzyme $(8.5$ to II.I mg protein $/ \mathrm{ml}), 0.03 ; \mathrm{NADH}(2.5 \mathrm{mM}), 0.02$. The constituents were added in the order stated. The reaction mixture, except for $\mathrm{NADH}$, was pre-incubated for $3 \mathrm{~min}$ in a water bath at $30{ }^{\circ} \mathrm{C}$ then transferred to the water-jacketed compartment (at $30{ }^{\circ} \mathrm{C}$ ) of a Zeiss PMQ II spectrophotometer. The reaction was started by adding NADH.

Cytochrome composition. The cultures were chilled, harvested and washed twice in water at $0{ }^{\circ} \mathrm{C}$, resuspended in water to a nominal cell density of 40 to $50 \mathrm{mg}$ dry wt/ml and frozen. Difference spectra (dithionite reduced versus ferricyanide oxidized) were determined on yeast prepared as follows. The frozen suspension was thawed and mixed throughly. Separate portions $(0.4 \mathrm{ml})$ were incubated for $2 \mathrm{~min}$ at room temperature with sodium dithionite $(50 \mathrm{mg} / \mathrm{ml}$ in $\mathrm{I} \cdot 0 \mathrm{M}$-tris buffer $\mathrm{pH} 7.6 ;$ Io $\mu \mathrm{l})$ and with potassium ferricyanide $(0.5 \mathrm{M} ; 5 \mu \mathrm{l})$. Difference spectra were measured at the temperature of liquid nitrogen in a split-beam spectrophotometer designed and built at the Johnson Foundation, University of Pennsylvania (Chance, I957). The low temperature cuvette (Bonner, I96I) had a path length of $2 \mathrm{~mm}$.

For all purposes the mass of yeast was determined on suspensions which had been washed twice with water and heated at $85^{\circ} \mathrm{C}$ for 3 days or $105{ }^{\circ} \mathrm{C}$ for 2 days.

Electronmicroscopy. The cultures were harvested after chilling, washed and fixed in glutaraldehyde, post-fixed with osmium tetroxide, and stained with uranyl acetate. The preparations were dehydrated in ethanol, embedded in Araldite and sectioned. Yeasts which had been grown in the presence of polyethylene glycol or glucose $(36 \%, \mathrm{w} / \mathrm{v})$ were initially washed in buffer containing 'half-strength' polyethylene glycol $(\mathrm{I} 6.6 \%, \mathrm{w} / \mathrm{w})$, a procedure found necessary to prevent extensive vacuolation.

\section{RESULTS}

\section{Respiration}

Table I summarizes respiration measurements with whole yeast in phosphate buffer and in buffer supplemented with polyethylene glycol. After growth in basal medium the $Q_{\mathrm{O}_{2}}$ (glucose) of S. cerevisiae was 22 to $23 \%$ higher than that of $S$. rouxii, whether measured in the presence or absence of added polyethylene glycol. Incubating either yeast in the presence of polyethylene glycol approximately halved the $Q_{\mathrm{o}_{2}}$. Growth at $0.95 a_{\mathrm{w}}$ in polyethylene glycol had little effect on the $Q_{\mathrm{o}_{2}}$ of $S$. rouxii in phosphate buffer but reduced the $Q_{\mathrm{O}_{2}}$ of $S$. cerevisiae by about $25 \%$. Both yeasts respired faster in buffered polyethylene glycol, however, giving $Q_{\mathrm{O}_{2}}$ values of about $80 \%$ of that obtained in buffer alone. Expressed another way, the $Q_{\mathrm{o}_{2}}$ in buffered polyethylene glycol was, for both yeasts, 30 to $60 \%$ higher after growth in polyethylene glycol than after growth in basal medium.

Growth in 24,36 and $48 \%$ glucose reduced the $Q_{\mathrm{O}_{2}}$ of $S$. rouxii by about $20 \%$ when measured in phosphate buffer. Within that range there was no effect which could be atributed to the concentration of glucose in the growth medium. The corresponding reduction in the $Q_{\mathrm{o}_{2}}$ of $S$. cerevisiae was about $75 \%$ after growth in 24 and $36 \%$ glucose (it does not grow in $48 \%$ glucose). The ratio of $\mathrm{Q}_{\mathrm{o}_{2}}$ in polyethylene glycol to $Q_{\mathrm{o}_{2}}$ in buffer alone was again higher for both yeasts than when they were grown in basal medium. For $S$. rouxii the $Q_{\mathrm{o}_{2}}$ in polyethylene glycol was absolutely higher than when the yeast was grown in basal medium. 
Table I. Respiration rates of whole yeast

\begin{tabular}{|c|c|c|c|}
\hline \multirow[b]{2}{*}{ Growth medium } & \multirow[b]{2}{*}{ Yeast } & \multicolumn{2}{|c|}{$Q_{\mathrm{O}_{2}}$ (glucose) $*$ measured in: } \\
\hline & & $\begin{array}{c}\text { Buffer } \\
\left(0.997 a_{\mathrm{w}}\right)\end{array}$ & $\begin{array}{l}\text { Buffer } \\
\text { and PEG } \\
\left(0.95 a_{\mathrm{w}}\right)\end{array}$ \\
\hline Basal & $\begin{array}{l}S . \text { cerevisiae } \\
\text { S. rouxii }\end{array}$ & $\begin{array}{l}95 \\
77\end{array}$ & $\begin{array}{l}44 \\
36\end{array}$ \\
\hline $\begin{array}{l}\text { Basal + PEG } \\
\quad\left(33.5 \%, w / w ; 0.95 a_{\mathrm{w}}\right)\end{array}$ & $\begin{array}{l}S . \text { cerevisiae } \\
\text { S. rouxii }\end{array}$ & 73.106 & $\begin{array}{c}57 \\
60,95\end{array}$ \\
\hline $\begin{array}{l}\text { Basal+glucose } \\
(24 \text { and } 36 \%, w / v) \\
(24,36 \text { and } 48 \%, w / v)\end{array}$ & $\begin{array}{l}\text { S. cerevisiae } \\
\text { S. rouxii }\end{array}$ & $\begin{array}{l}22 \\
63\end{array}$ & $\begin{array}{l}18 \\
42 \\
(5 \mathrm{I}) \dagger\end{array}$ \\
\hline
\end{tabular}

The reaction vessels contained: phosphate buffer or phosphate buffer+PEG $(33.5 \%$, w/v) (see text), $2.3 \mathrm{ml}$; yeast suspension (see text), $0.4 \mathrm{ml}$; glucose (10\%, w/v) $0.3 \mathrm{ml}$, side arm; $\mathrm{KOH}(20 \%$, w/v), $0.2 \mathrm{ml}$, centre well.

* The overall standard deviation for $Q_{\mathrm{O}_{2}}$ was $\pm 3 \%$ of the stated value. An exception was $S$. rouxii grown in basal+PEG, under which conditions duplicate preparations gave the values shown.

$\dagger$ Grown in $24 \%(\mathrm{w} / \mathrm{v})$ glucose and measured in $16.8 \%$ (w/w) PEG. (With $S$. cerevisiae there was no difference in $Q_{O_{2}}$ between yeast grown in $36 \%$ glucose and measured in $33.5 \% \mathrm{PEG}$, and yeast grown in $24 \%$ glucose and measured in $16.8 \%$ PEG.

Table 2. NADH oxidase activity of mitochondrial preparations

\begin{tabular}{clc} 
Growth medium & \multicolumn{1}{c}{ Yeast } & $\begin{array}{c}\text { NADH oxidase } \\
\text { activity* } \\
(\mu \text { moles } / m i n \\
\text { protein })\end{array}$ \\
Basal & $\begin{array}{l}\text { S. cerevisiae } \\
\text { S. rouxii }\end{array}$ & $35 \cdot 8$ \\
Basal + PEG & S. cerevisiae & $31 \cdot 9$ \\
$(33 \cdot 5 \%, \mathrm{w} / \mathrm{w})$ & S. rouxii & $\mathrm{I} 5 \cdot 8-\mathrm{I} 9 \cdot 4$ \\
Basal + glucose & S. cerevisiae & $20 \cdot \mathrm{I}-34 \cdot 2$ \\
$(36 \%, \mathrm{w} / \mathrm{v})$ & S. rouxii & $3 \cdot 5$ \\
$(36 \%, \mathrm{w} / \mathrm{v})$ & S. rouxii & $2 \mathrm{I} \cdot 9$ \\
$(48 \%, \mathrm{w} / \mathrm{v})$ & & $14 \cdot 4$
\end{tabular}

* Replicate preparations normally gave values within $5 \%$ of the mean. Organisms grown in basal+PEG were exceptional and gave preparations with activities in the ranges shown (cf. Table I).

\section{NADH oxidase}

A similar general trend is shown in Table 2 for the NADH oxidase activity of mitochondria preparations. The specific activity of preparations from $S$. cerevisiae was about $12 \%$ higher than corresponding preparations from $S$. rouxii when both yeasts were grown in basal medium. As with $Q_{\mathrm{o}_{2}}$, there was more variation among preparations of yeast grown in the presence of polyethylene glycol. Saccharomyces rouxii preparations were probably not affected by growth in polyethylene glycol; they were certainly not significantly affected. The NADH oxidase activity of $S$. cerevisiae mitochondria was lowered by 46 to $56 \%$ under these conditions.

Unlike $Q_{0_{2}}$, NADH oxidase activity of mitochondrial preparations from $S$. rouxii responded to the glucose concentration of the growth medium within the range of 36 to $48 \%(\mathrm{w} / \mathrm{v})$. Growth in $48 \%$ glucose halved the activity; growth in $36 \%$ glucose reduced it 
$(A)$
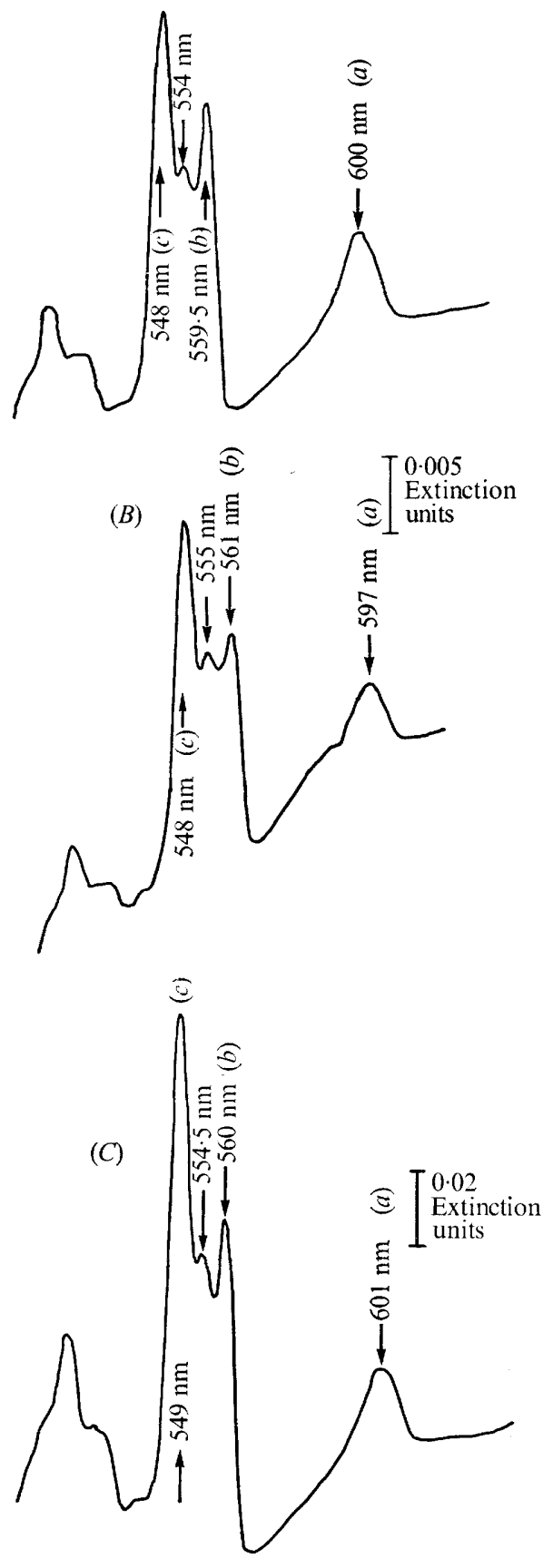
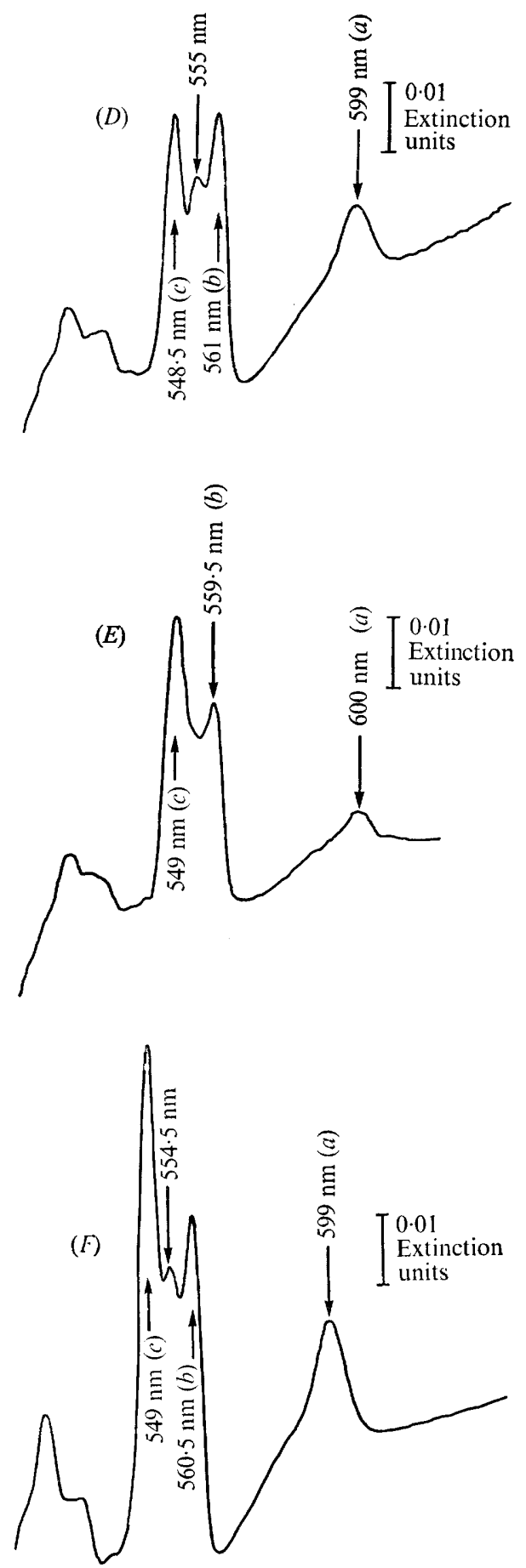

Fig. I. Absorption spectra (dithionite reduced versus ferricyanide oxidized) of yeast suspensions at $77^{\circ} \mathrm{K}$. (A) Saccharomyces cerevisiae grown in basal medium. Suspension density $45 \cdot 3 \mathrm{mg} / \mathrm{ml}$. (B) Saccharomyces rouxii grown in basal medium. Suspension density $38.5 \mathrm{mg} / \mathrm{ml}$. (C) Saccharomyces cerevisiae grown at $0.95 a_{\mathrm{w}}$ in polyethylene glycol. Suspension density $43.0 \mathrm{mg} / \mathrm{ml}$. (D) Saccharomyces rouxii grown at $0.95 a_{\mathrm{w}}$ in polyethylene glycol. Suspension density $5 \mathrm{I} \cdot 6 \mathrm{mg} / \mathrm{ml}$. (E) Saccharomyces cerevisiae grown in $36 \%$ (w/v) glucose. Suspension density $40.0 \mathrm{mg} / \mathrm{ml}$. (F) Saccharomyces rouxii grown in $36 \%$ (w/v) glucose. Suspension density $40.0 \mathrm{mg} / \mathrm{ml}$. 
Table 3. Relative cytochrome contents of the two yeasts

\begin{tabular}{llcc} 
Growth medium & \multicolumn{1}{c}{ Yeast } & $\begin{array}{c}\text { 'Cytochrome } c \text { ' } \\
\text { (units*/I00 mg) }\end{array}$ & $\begin{array}{c}\text { 'Cytochrome } b \text { ' } \\
\text { (units*/I00 mg) }\end{array}$ \\
Basal & S. rouxisiae & 0.238 & 0.185 \\
Basal+PEG & S. cerevisiae & 0.057 & 0.037 \\
$(33.5 \%, \mathrm{w} / \mathrm{w})$ & S. rouxii & 0.344 & 0.212 \\
Basal+glucose & S. cerevisiae & 0.076 & 0.076 \\
$(36 \%, \mathrm{w} / \mathrm{v})$ & S. rouxii & 0.103 & 0.072 \\
& & 0.186 & 0.123
\end{tabular}

* Units for 'cytochrome $c$ ': extinction units, 548 or 549 to $570 \mathrm{~nm}$; units for 'cytochrome $b$ ': extinction units, 560 or 561 to $570 \mathrm{~nm}$.

by about $30 \%$. In marked contrast, however, growth in $36 \%$ glucose reduced the NADH oxidase of $S$. cerevisiae mitochondrial preparations to less than $10 \%$ of the original value.

\section{Cytochrome absorption spectra}

The cytochrome composition of the yeast is illustrated in Fig. I. The two species were qualitatively similar although there were some minor differences in the wavelength of the $\alpha$-bands of cytochromes $a$ and $b$. There were, however, major quantitative differences, approximately summarized in Table 3 , for cytochromes $b$ and $c$. When grown in basal medium $S$. cerevisiae had 4 to 5 times as much cytochrome $b$ and $c$ as did $S$. rouxii. When they were grown at $0.95 a_{\mathrm{w}}$ in polyethylene glycol, the cytochrome content of each yeast was increased. The proportional increase in cytochrome $c$ was similar in both yeasts, but the cytochrome $b$ content of $S$. rouxii was about doubled and its peak height equalled that of cytochrome $c$.

The two yeasts had opposite responses to growth in $36 \%$ glucose. The cytochrome $b$ and $c$ content of S. cerevisiae was halved and the small peak of about $555 \mathrm{~nm}$ disappeared, whereas the apparent overall cytochrome content of $S$. rouxii increased about threefold and the content of cytochromes $b$ and $c$ was about twice as great as that of $S$. cerevisiae.

\section{Electronmicroscopy}

The major structural changes which were observed occurred in S.'cerevisiae; similar changes have been amply described and illustrated by other authors (e.g. Linnane, Vitols \& Nowland, I962; Yotsuyanagi, I962; Wallace, Huang \& Linnane, I968). Saccharomyces rouxii responded only to a minor extent to variations in the composition of the growth medium. When they were grown in basal medium the two yeasts had a similar fine structure and contained a similar number of mitochondrial profiles [S. cerevisiae $8 \cdot 9 \pm \mathrm{I} \cdot 7$ (S.E.M.) and $S$. rouxii $7 \cdot 4 \pm 0.8$ /equatorial section]. When grown in the presence of polyethylene glycol at $0.95 a_{\mathrm{w}}$ some differences were evident. Saccharomyces cerevisiae had more mitochondria $(\mathrm{I} 5 \cdot 8 \pm \mathrm{I} \cdot 2)$ than $S$. rouxii $(6 \cdot \mathrm{I} \pm 0 \cdot 7)$ but the mitochondria were somewhat larger in $S$. rouxii. When grown in $36 \%$ glucose, mitochondrial numbers were again similar and not very different from those of the yeasts grown in basal medium (S. cerevisiae, $7 \cdot 2 \pm \mathrm{I} \cdot 0 ; S$. rouxii, $6 \cdot 6 \pm 0.7)$. The 'mitochondrial' profiles in $S$. cerevisiae had little or no internal structure, however, whereas those of $S$. rouxii appeared normal and contained cristae. 
DISCUSSION

There is nothing novel in the observation that growth in a relatively high glucose concentration represses respiratory activity and mitochondrial formation in Saccharomyces cerevisiae (Slonimski, 1953; Ephrussi, Slonimski, Yotsuyanagi \& Tavlitzki, 1956; Yotsuyanagi, 1962; Tustanoff \& Bartley, I964; Utter, Duell \& Bernofsky, 1968). The comparison with the related species, $S$. rouxii, is of interest for several reasons, one being the common assumption that this type of catabolite repression is characteristic of the genus Saccharomyces.

The high glucose concentrations used in the present series of experiments presumably affected the results by at least two processes of major significance, one involving the relatively non-specific physico-chemical effects of a concentrated non-electrolyte in the growth medium, the other the much more specific effects of catabolite repression. Although it is now clear that the role of non-electrolytes in the apparent water relations of yeast is more than simply that of a non-specific solute which produces a certain water activity $\left(a_{\mathrm{w}}\right)$ in the extracellular fluid (Anand \& Brown, I968; Brown \& Simpson, 1972), the response of any one organism to changes in extracellular solute concentration is usually qualitatively similar for many different non-electrolytes.

Thus it is reasonable to assume that incorporation into the growth medium of polyethylene glycol, which is not metabolized, produced an effect which, at least as a first approximation, resembled the purely physico-chemical influences of high glucose concentration. At this level there were differences between the two species but they were of relatively minor proportions. Growth in polyethylene glycol slightly lowered $Q_{\mathrm{O}_{2}}$ in $S$. cerevisiae but not in $S$. rouxii, halved NADH oxidase activity in $S$. cerevisiae but not in $S$. rouxii, and increased the cytochrome $b+c$ content of both species. It also caused in both species a degree of adaptation to polyethylene glycol as reflected in the enhanced respiration rates of yeast suspended on polyethylene glycol.

In some respects growth in high concentrations of glucose resembled growth in polyethylene glycol but, on balance, it caused very large differences beween the two species. Following on from the comments above, a major factor in these differences can be assumed to be different responses of the two species to the specific repressive action of glucose metabolism. The similarities between the two solutes were evident in the adaptation by both yeasts to polyethylene glycol as a suspending solution of $\mathrm{O}_{2}$-uptake measurements. This adaptation is reflected in Table I in the ratio of $Q_{\mathrm{O}_{2}}$ in polyethylene glycol to $Q_{\mathrm{o}_{2}}$ in buffer alone after growth in the three media. The nature of the adaptation mechanism is not known but increased permeability to glucose of the yeasts and/or their mitochondria is a possibility. The other important similarity is that growth in a high glucose concentration increased the cytochrome content of $S$. rouxii; indeed, the increase was much greater than produced by polyethylene glycol.

In this and all other measured properties, however, the two yeasts differed profoundly from each other after growth in high concentrations of glucose. By all the criteria used, the capacity of $S$. cerevisiae to respire was greatly reduced by 24 and $36 \%(w / v)$ glucose in the growth medium, as was to be expected (see above). The corresponding effect on the $Q_{\mathrm{o}_{2}}$ of $S$. rouxii was minor, and was associated with mutually opposing trends in the response of NADH oxidase activity on the one hand and cytochrome content on the other.

Part of the effect of glucose on $S$. rouxii can be assumed to have been caused by direct physico-chemical effects of a non-electrolyte and part by the differences which must inevitably occur in any system when the quantitative details of metabolism are changed. Whether or not catabolite repression specifically contributed to the slight reduction in $Q_{\mathrm{O}_{2}}$ 
and somewhat greater reduction in NADH oxidase activity caused by glucose in $S$. rouxii is doubtful. If it did, the contribution was obviously of minor significance.

The failure of glucose metabolism to repress the respiratory capacity of $S$. rouxii is potentially explicable in two ways: the mechanism of gene expression, at least for the biogenesis of the respiratory chain, is different in the two species and, in $S$. rouxii, is not inherently susceptible to catabolite repression; or the repression mechanism is overcome by arabitol. Arabitol accumulates to a high concentration in $S$. rouxii (Brown \& Simpson, 1972; Brown, 1974) and protects enzymes against inactivation at low levels of water activity (Brown \& Simpson, 1972) as does glycerol in halophilic algae (Borowitzka \& Brown, I974) and $\mathrm{K}^{+}$(and $\mathrm{KCl}$ ) in halophilic bacteria (Aitken \& Brown, 1972). It is conceivable that arabitol at such high concentrations as exist in $S$. rouxii could change the overall kinetics of gene expression in such a way that catabolite repression, of the kind under discussion, does not occur. Indeed, according to one report (Wallis, Ottolenghi \& Whittaker, I972), incubation of $S$. cerevisiae in $2 \%$ glycerol can induce mutation of the yeast to a petite form. The possibility that arabitol does modify gene expression is amenable to investigation and clearly warrants it.

The sugar-tolerant yeasts must be able to resist catabolite repression of respiration if they are to thrive at the very high sugar concentrations which can occur in their normal habitats. To grow under such conditions they must produce their compatible solute, a polyol. Although the detailed mechanisms of polyol production are obscure it is an empirical observation that polyol formation is favoured by aerobic conditions and hindered by an oxygen deficiency (Onishi, 1963; Spencer, 1968). Since repression or inhibition of respiration would be tantamount to anaerobiosis, the yeast must be able to retain its respiratory capacity if it is to synthesize its compatible solute. It thus provides another example of the ramifications of adaptation to an extreme environmental situation.

This work was supported by the Nuffield Foundation (Australia) and was undertaken with the technical assistance of Miss Robyn Yabsley. I thank Dr C. D. Shorey of the Electronmicroscope Unit, University of Sydney, Australia, for the electronmicrographs on which statements in the text were based. I also thank Dr R. A. Cox for the absorption spectra which were obtained during a brief visit by the writer to the Biochemistry Department, University of Cambridge.

\section{REFERENCES}

Aitken, D. M. \& BRown, A. D. (I972). Properties of halophil nicotinamide-adenine dinucleotide phosphatespecific isocitrate dehydrogenase. True Michaelis constants, reaction mechanisms and molecular weights. Biochemical Journal 130, 645-662.

ANAND, J. C. (1969). The physiology and biochemistry of sugar-tolerant yeasts. Ph.D. thesis, University of New South Wales, Australia.

ANAND, J. C. \& Brown, A. D. (I968). Growth rate patterns of the so-called osmophilic and non-osmophilic yeasts in solutions of polyethylene glycol. Journal of General Microbiology 52, 205-2 I 2.

BonNeR, W. D. (196I). The cytochromes of plant tissues. In Haematin Enzymes, part 2, pp. 479-497. Edited by J. E. Falk, R. Lemberg and R. K. Morton. Oxford: Pergamon Press.

Borowitzka, L. J. \& Brown, A. D. (I974). The salt-relations of marine and halophilic species of the unicellular green alga, Dunaliella. The role of glycerol as a compatible solute. Archiv für Mikrobiologie 96, $37-52$.

Brown, A. D. (1974). Microbial water relations. Features of the intracellular composition of sugar-tolerant yeasts. Journal of Bacteriology 118, 769-777.

Brown, A. D. \& Simpson, J. R. (1972). Water relations of sugar-tolerant yeasts: the role of intracellular polyols. Journal of General Microbiology 72, 589-59I. 
Chance, B. (1957). Techniques for the assay of the respiratory enzymes. In Methods in Enzymology, vol. 4, pp. 273-329. Edited by S. P. Colowick and N. O. Kaplan. New York: Academic Press.

Ephrussi, B., Slonimski, P. P., Yotsuyangi, Y. \& Tavlitzki, (1956). Variations physiologiques et cytologiques de la levure au cours du cycle de la croissance aérobie. Carlsberg Laboratoriet Comptes rendus des travaux du Laboratoire Carlsberg (Serie physiologique) 26, 87-102.

Linnane, A. W., Vitols, E. \& Nowland, P. G. (1962). Studies on the origin of yeast mitochondria. Journal of Cell Biology 13, 345-350.

ONisHI, H. (1963). Osmophilic yeasts. Advances in Food Research 12, 53-93.

SLonimski, P. P. (1953). La Formation des Enzymes Respiratoires chez la Levure. Paris: Masson et Cie.

SPENCER, J. F. T. (1968). Production of polyhydric alcohols by yeasts. Progress in Industrial Microbiology 7, I-42.

TUSTANOFF, E. R. \& BARTLEY, W. (1964). Development of respiration in yeast grown anaerobically on different carbon sources. Biochemical Journal 91, 595-600.

Utter, M. F., Duell, E. A. \& Bernofsky, C. (1968). Alterations in the respiratory enzymes of the mitochondria of growing and resting yeast. In Aspects of Yeast Metabolism, pp. 197-212. Edited by A. K. Mills. Oxford: Blackwell Scientific Publications.

Wallace, P. G., Huang, M. \& Linnane, A. W. (I968). The biogenesis of mitochondria. II. The influence of medium composition on the cytology of anaerobically grown Saccharomyces cerevisiae. Journal of Cell Biology 37, 207-220.

Wallis, O. C., OtTolenghi, P. \& WhitTaker, P. A. (1972). Induction of petite mutants in yeast by starvation in glycerol. Biochemical Journal 127, 46-47 P.

YotsuYANAGI, Y.(1962). Études sur la chondriome de la levure. I. Variation de l'ultrastructure du chondriome au cours du cycle de la croissance aérobie. Journal of Ultrastructure Research 7, 121-140. 